
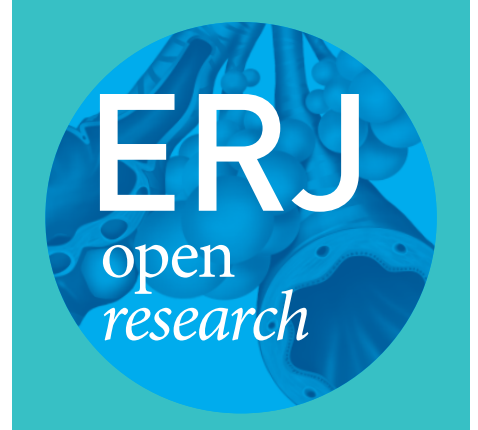

\section{Management of the patient with eosinophilic asthma: a new era begins}

\author{
Jantina C. de Groot ${ }^{1}$, Anneke ten Brinke ${ }^{1}$ and Elisabeth H.D. Bel ${ }^{2}$ \\ Affiliations: 'Department of Respiratory Medicine, Medical Centre Leeuwarden, Leeuwarden, The Netherlands. \\ ${ }^{2}$ Department of Respiratory Medicine, Amsterdam Medical Centre, Amsterdam, The Netherlands.
}

Correspondence: Jantina C. de Groot, Department of Respiratory Medicine, Medical Centre Leeuwarden, Henri Dunantweg 2, 8934 AD Leeuwarden, The Netherlands. E-mail: Christa_de_grootayahoo.com

ABSTRACT Now that it is generally accepted that asthma is a heterogeneous condition, phenotyping of asthma patients has become a mandatory part of the diagnostic workup of all patients who do not respond satisfactorily to standard therapy with inhaled corticosteroids. Late-onset eosinophilic asthma is currently one of the most well-defined asthma phenotypes and seems to have a different underlying pathobiology to classical childhood-onset, allergic asthma. Patients with this phenotype can be identified in the clinic by typical symptoms (few allergies and dyspnoea on exertion), typical lung function abnormalities ("fixed" airflow obstruction, reduced forced vital capacity and increased residual volume), typical comorbidities (nasal polyposis) and a good response to systemic corticosteroids. The definitive diagnosis is based on evidence of eosinophilia in bronchial biopsies or induced sputum, which can be estimated with reasonable accuracy by eosinophilia in peripheral blood. Until recently, patients with eosinophilic asthma had a very poor quality of life and many suffered from frequent severe exacerbations or were dependent on oral corticosteroids. Now, for the first time, novel biologicals targeting the eosinophil have become available that have been shown to be able to provide full control of this type of refractory asthma, and to become a safe and efficacious substitute for oral corticosteroids.

@ERSpublications

Late-onset eosinophilic asthma has a distinct clinical and functional profile with treatment implications http://ow.ly/MH7AH

Received: May 52015 | Accepted: May 52015

Disclosures can be found alongside this article at openres.ersjournals.com

Copyright $\odot$ ERS 2015. This article is open access and distributed under the terms of the Creative Commons Attribution Non-Commercial Licence 4.0. 


\section{Introduction}

Over recent decades, asthma has come to be no longer been considered a single disease but a collection of different conditions with overlapping symptomatology but diverse aetiologies [1]. The importance of defining subtypes has been increasingly recognised and multiple subphenotypes of asthma have been identified based on clinical, functional or inflammatory parameters [2-5]. Probably the most consistent and clinically relevant phenotype is late-onset eosinophilic asthma [6,7]. Patients with this phenotype show persistent eosinophilic airway inflammation despite treatment with inhaled corticosteroids (ICS), which is associated with more severe disease and a poorer prognosis [8-12]. Recognition of this relatively rare phenotype in the clinic has now become even more important, since targeted therapies, such as monoclonal antibodies against interleukin (IL)-5, have been developed and will soon become available [13, 14]. These novel treatment options are very promising and could, for the first time, eliminate the unmet needs of patients with severe, late-onset eosinophilic asthma, and become a safe and effective substitute for systemic corticosteroids [15]. In this review, we describe the clinical, pathophysiological and management aspects of this specific asthma phenotype, in order to provide the clinician with tools for its early recognition, enabling targeted treatment of these patients.

\section{Asthma phenotypes and the role of the eosinophil}

Phenotyping of asthma is not new. As early as in 1947, RACKEMANN [16] pointed out that different subtypes of asthma existed. Around that time, asthma was considered an illness characterised by "spasmodic afflictions of the bronchial tubes" with a good response to the bronchodilating agent isoprenaline [17]. The most common assumption was that an allergic trigger was responsible for airway obstruction and symptoms of asthma. Rackemann challenged this theory by stating "Even the 'allergists' now recognize that 'all is not allergy that wheezes". In his paper "Intrinsic asthma" [18], he described patients with adult-onset asthma, without any sign of allergy, but with a more severe course of the disease, including several fatalities. In an animated discussion, he and his colleagues wondered what the initiating trigger of "intrinsic asthma" might be. Was it allergy at all? Was it allergy to drugs, such as aspirin? Was it allergy to bacteria, yet to be identified? Was it related to a nerve reflex from the nose or sinuses? Or was it due to an infection? This latter option was considered less likely, as high levels of blood eosinophils were observed rather than neutrophils. Rackemann made a plea for further research into this nonallergic asthma subtype: "Surely it is hard to believe that the wheeze which comes to the young school girl in the middle of the ragweed season is the same disease as that which develops suddenly in the tired business man and pushes him down to the depths of despair" [16].

Despite this visionary plea for asthma phenotyping, asthma continued to be regarded as a single disease that was strongly associated with allergy, particularly in children [19]. From 1963, an increasing number of papers was published on the increases in the prevalence of allergies and asthma in children and young adults [20, 21]. This "epidemic" of allergy and asthma was thought to be related to increased exposure to sensitising allergens and reduced stimulation of the immune system during critical periods of development [22]. Risk factors with the best potential for primary prevention included parental smoking, breastfeeding, dietary factors and, most importantly, indoor allergens [23].

In the meantime, significant progress was made in the development of new asthma treatments. Following on from the success in rheumatoid arthritis, the first small trial of adrenocorticotropic hormone in asthma was reported in 1949 [24]. Since then, several studies have confirmed the beneficial effects of glucocorticoids in asthma and by the 1970s, systemic corticosteroids were accepted as the standard therapy to treat and prevent asthma exacerbations [25]. Because of the serious side-effects of this therapy, ICS were developed and introduced in 1973 with a much better risk-benefit profile [26]. Until today, ICS have been the mainstay of asthma treatment.

The concept of asthma as a single condition with one uniform therapy began to falter due to the observation that a small subset of asthma patients were not controlled on even high doses of ICS, so-called "difficult asthma" patients [27]. In addition, it became clear that specific subgroups of asthma patients could be identified, either on the basis of clinical characteristics (with or without frequent exacerbations) [28], age of asthma onset (childhood onset versus adult onset) [29], lung function abnormalities (with or without persistent airflow limitation) [11], trigger factors (allergic, nonallergic or aspirin induced) [30] or type of airway inflammation (eosinophilic versus noneosinophilic) [30]. In 1999, WENZEL et al. [31] were the first to describe a specific phenotype of severe asthma characterised by persistent eosinophils in bronchial biopsies despite high-dose inhaled and/or oral corticosteroid treatment, which they called "eosinophil-positive severe asthma". Almost 10 years later, a breakthrough in clinical asthma phenotyping came from studies that used cluster analysis to identify different subphenotypes of asthma in a more objective way [32-35]. These clusters varied with respect to the severity of symptoms, age of asthma onset, degree of airflow limitation or type of airway inflammation, but most analyses suggest that adult patients 
are likely to fall into one of five clusters [1, 36, 37]. Remarkably, some cluster analyses identified a phenotype of patients with late-onset eosinophilic asthma that was clearly distinct from the classical "allergic asthma" phenotype $[33,34]$. In the following sections, we will discuss in more detail the clinical profile, pathophysiological mechanisms, management and novel therapeutic options for this eosinophilic asthma phenotype.

\section{Molecular pathways of eosinophilic inflammation}

Eosinophils are bone marrow-derived granulocytes that have long been recognised as the major inflammatory cells involved in the pathobiology of both childhood-onset, allergic asthma and adult-onset, nonallergic asthma [38]. In patients with childhood-onset, allergic asthma, numbers of eosinophils increase after exposure to specific allergens [39]. This allergic response is often manifested as a dual reaction, consisting of an early-phase response that involves mainly mast cell degranulation [40], followed by a late-phase response in which a secondary infiltration of cells occurs in the airways [41]. Eosinophils comigrate with inflammatory cells and frequently undergo degranulation, releasing a range of cytotoxic products including major basic protein, eosinophil cationic protein, eosinophil-derived neurotoxin and eosinophil peroxidase [42]. They also produce a variety of cytokines and chemokines that further contribute to airway epithelial damage, oedema, mucus overproduction from goblet cells and bronchial hyperresponsiveness [43].

In childhood-onset, allergic asthma, T-helper (Th)2 cells are believed to drive the immune response, as greater expression of Th2 cytokines including IL-4, IL-5 and IL-13 is seen in allergen-challenged individuals, along with downregulation of Th1 cytokines (IL-2 and interferon- $\gamma$ ) [43]. IL-4 promotes Th2 cell development and B-cell isotype switching, and it affects the production of chemokines by the airway epithelium [44]. IL-5 plays an important role in the migration, maturation and survival of eosinophils, and IL-13 has been shown to cause airway inflammation, increased mucous secretion, subepithelial fibrosis and eotaxin production [45]. Furthermore, IL-13 has also been shown to increase airway hyperresponsiveness [46].

However, the cytokine network associated with asthma in humans is complex and eosinophilia is not always associated with allergic inflammation or the atopic asthma phenotype [47]. For example, several studies suggest that although IL-4 triggers the polarisation of T-cells to a Th2 phenotype, it is not necessary for the manifestation of eosinophilic inflammation in asthma [48].

Adult-onset eosinophilic asthma frequently develops in the absence of allergen-dependent activation of Th2 lymphocytes, which suggests a distinct underlying mechanism of eosinophilic inflammation apart from allergy. Recent evidence suggests that innate lymphoid cells (ILCs) have a central role in driving this type of eosinophilic asthma [49-51]. High numbers of ILC2s have been detected in airways and blood from patients with asthma [52] as well as in eosinophilic nasal polyps [53], a frequently observed comorbidity in late-onset eosinophilic asthma [54]. ILCs can be activated in an allergen-independent manner by IL-25, IL-33 and thymic stromal lymphopoietin [55], which are released from bronchial epithelial cells upon stimulation with viruses, fungal allergens and air pollutants. Production of cytokines by these cells is also stimulated by prostaglandin $\mathrm{D}_{2}$ via activation of its chemoattractant receptor-homologous molecule receptor [56]. Like Th2 cells, activated ILCs produce high amounts of IL-5 and IL-13, and are capable of inducing eosinophilic airway inflammation independent of T-cells (fig. 1) [50]. In addition, ILC2s have been shown to be essential for the persistence of asthma [57].

Thus, in asthma, two different pathways driven by either allergen-specific Th2 cells or allergen-independent ILC2s may lead to production of IL-5, which induces eosinophilic airway inflammation.

\section{Clinical profile of the patient with eosinophilic asthma}

The term "eosinophilic asthma" describes a subphenotype of asthma that is characterised by elevated levels of eosinophils in bronchial biopsies or sputum despite chronic and correct use of adequate doses of ICS [58-61]. The exact prevalence of eosinophilic asthma is not known but one study in patients with difficult asthma on high-dose inhaled and/or oral corticosteroids showed that of 44 patients, 14 (32\%) exhibited sputum eosinophilia $(\geqslant 2 \%)$ on two occasions with a 5 years apart [62]. By extrapolating these figures to the entire asthma population [63], one could estimate that about $5 \%$ of all adult asthma patients would fulfil the criteria of the eosinophilic asthma phenotype.

Apart from eosinophilic airway inflammation that is relatively steroid resistant, the eosinophilic asthma phenotype is characterised by specific clinical, functional and inflammatory characteristics and comorbidities [6] (table 1).

The eosinophilic asthma phenotype appears to be more common in patients with adult-onset asthma than in those with childhood-onset asthma [29]. The average age of onset is 25-35 years of age [33, 61, 62] and, 


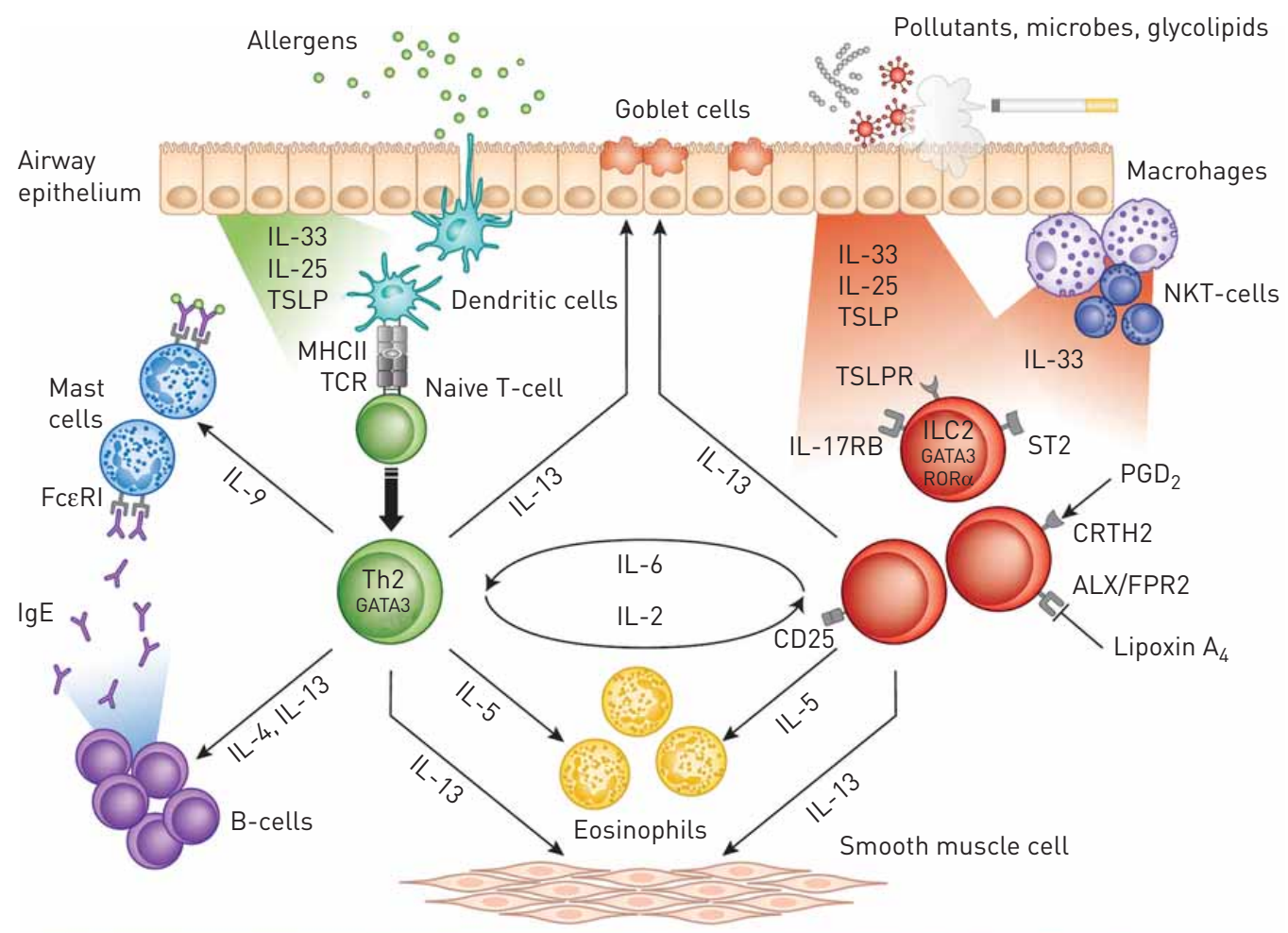

Allergic eosinophilic airway inflammation

Nonallergic eosinophilic airway inflammation

FIGURE 1 Two different pathways lead to eosinophilic airway inflammation in asthma. In allergic asthma, dendritic cells present allergens to $\mathrm{CD} 4^{+} \mathrm{T}$-cells, inducing T-helper (Th) 2 cells, which produce interleukin (IL)- 4 , IL-5 and IL-13, and leading to IgE switching in B-cells, airway eosinophilia and mucous hypersecretion. In nonallergic eosinophilic asthma, air pollutants, microbes and glycolipids induce the release of epithelium-derived cytokines, including IL-33, IL-25 and thymic stromal lymphopoietin (TSLP), which activate innate lymphoid cells (ILCs) in an antigen-independent manner via their respective receptors (IL-17 receptor B (IL-17RB), ST2 and TSLP receptor (TSLPR)). Activated ILC2s produce high amounts of IL-5 and IL-13, leading to eosinophilia, mucus hypersecretion and airway hyperreactivity. CRTH2: chemoattractant receptor homologous molecule expressed on Th2 cells; ALX/FPR2: receptor for lipoxin $\mathrm{A}_{4}$; FceRI: high-affinity receptor for IgE; GATA3: GATA-binding protein 3; PG: prostaglandin; ROR: retinoic acid receptor-related orphan receptor; NK: natural killer; MHC: major histocompatibility complex; TCR: T-cell receptor. Reproduced from [51] with permission from the publisher.

while adult asthma generally shows a female preponderance [64], eosinophilic asthma appears to be more equally distributed between males and females $[33,62]$.

Patients with late-onset eosinophilic asthma are less often typically allergic than other adults with asthma $[29,62,65]$. However, although not sensitised to common inhaled allergens [33], many patients have elevated

\section{TABLE 1 Clinical profile of late-onset eosinophilic asthma patients}

Adult onset of asthma

Equal distribution between sexes

Few or no allergies to common allergens

Elevated eosinophils in peripheral blood

At risk of severe exacerbations

Normal or moderately elevated IgE level

Low FEV1 and often persistent airflow limitation

Air trapping and dynamic hyperinflation

Chronic rhinosinusitis with nasal polyposis

Aspirin sensitivity

Good response to systemic corticosteroids

Good response to anti IL-5 treatment

FEV1: forced expiratory volume in $1 \mathrm{~s}$; IL: interleukin. 
levels of total IgE, which may be linked to hidden allergens, such as superantigens against Staphylococcus aureus $[66,67]$. In addition, late-onset eosinophilic asthma is often associated with sensitivity to nonsteroidal anti-inflammatory medications (aspirin) [29, 30].

Several studies have shown that late-onset eosinophilic asthma is associated with more severe disease than noneosinophilic asthma [8,31]. High levels of eosinophils in sputum [68] and bronchial biopsies [69] are associated with poor asthma control, more severe asthma [70] and fatal or near-fatal asthma attacks [71]. In a biopsy study of patients with severe asthma, it appeared that the patients who had eosinophilic inflammation despite systemic corticosteroids had an almost 20 times higher odds of being intubated than those without eosinophilic inflammation [31]. In patients who died from asthma, significantly more eosinophils were found in large and small airways, as compared to biopsies from patients with milder exacerbations [72].

Late-onset eosinophilic asthma is also associated with lower forced expiratory volume in $1 \mathrm{~s}(\mathrm{FEV} 1)$ and airflow limitation that is not fully reversible with bronchodilators [11, 29, 32, 73, 74]. In addition, peripheral airways are more involved in the inflammatory process than in other adults with asthma, as was shown by a lower forced vital capacity (FVC)/slow vital capacity and higher levels of alveolar nitric oxide in patients with eosinophilic asthma $[31,75]$.

Another characteristic feature of late-onset eosinophilic asthma is chronic rhinosinusitis with nasal polyposis [76]. The association between peripheral blood eosinophilia, nasal polyposis and asthma has been recognised for many decades, in particular in combination with aspirin sensitivity [30, 77-81]. This association has been confirmed in a study in adults with difficult-to-control asthma, showing that severe sinus disease was a strong independent predictor of persistent eosinophilia in blood or sputum [54]. Mucosal inflammation in these patients might extend even to the middle ears. In 2011, a newly recognised middle ear disease, eosinophilic otitis media, was described, characterised by a highly viscous, eosinophil-predominant middle ear effusion causing progressive deterioration of hearing. This otitis is associated with asthma and nasal polyps, and responds to prednisone, whereas other treatments for otitis media failed [82, 83].

Thus, late-onset eosinophilic asthma is characterised by systemic inflammation and involves the whole respiratory tract, from the paranasal sinuses to the very distal airways. Treatment with inhaled steroids, even at very high doses, is often not sufficient to obtain control of the disease, probably because peripheral airways and paranasal sinuses cannot be reached adequately with inhaled or topical corticosteroids $[84,85]$. It has been demonstrated repeatedly that systemic corticosteroids can blunt the eosinophilic inflammatory process and improve asthma symptoms $[86,87]$ and that the apparent resistance to corticosteroids in this asthma phenotype is only relative (fig. 2).

\section{Management of the patient with eosinophilic asthma}

Early identification of patients with eosinophilic asthma in clinical practice is important because these patients are at risk of poor asthma outcome $[11,88,89]$, which has implications for asthma management. However, identifying these patients in day-to-day practice may not be easy. The typical patient with "eosinophilic asthma" is relatively uncommon [90] and has few symptoms despite active airway inflammation [33].

FIGURE 2 Effect of high dose triamcinolone on sputum eosinophils. Effect of treatment with intramuscular triamcinolone or placebo on sputum eosinophil percentages in 22 patients with eosinophilic asthma. Horizontal lines represent median values. Reproduced and modified from [87] with permission from the publisher.
- Patients using corticosteroids daily $\square$ Patients not using corticosteroids daily

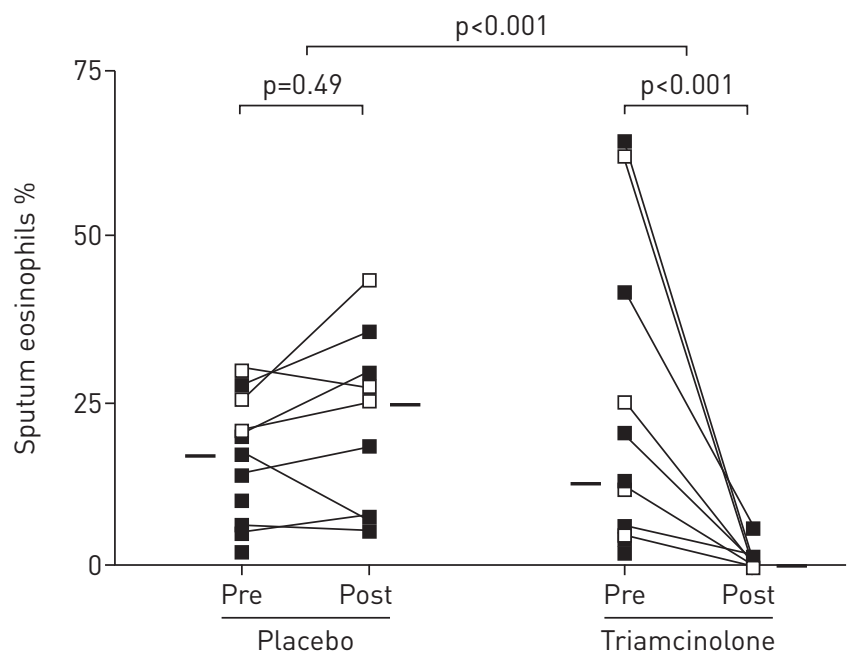


This is probably explained by a blunted perception of dyspnoea, as has been shown in severe asthma patients with high levels of sputum eosinophils [91]. These symptoms are also atypical, with more pronounced dyspnoea on exertion instead of wheezy attacks, which is related to dynamic hyperinflation due to distal airway inflammation $[31,75]$. Most patients with eosinophilic asthma have an adult onset of their disease, are nonatopic and have fixed airflow limitation $[11,29]$. Taken together, these symptoms and signs differ greatly from those of classical childhood-onset, allergic asthma and may be indistinguishable from those of chronic obstructive pulmonary disease (COPD) [92]. In line with this, a recent study evaluating the effect of a new biological in severe prednisone-dependent asthma patients [15] showed greater improvement in the St George's Respiratory Questionnaire score, a questionnaire that is primarily designed for COPD patients, than in the Asthma Control Questionnaire score. The treating physician may therefore easily misdiagnose the patient with eosinophilic asthma and, more importantly, prescribe inadequate treatment. Indeed, treating a patient with persistent eosinophilia with bronchodilators alone, without corticosteroids, is undesirable and may even be associated with increased morbidity and mortality [71, 72, 93].

In order to make the correct diagnosis, a few items in the history and physical examination may be of help. If a patient has a negative or limited smoking history $(<15$ years $)$ and no history of occupational exposures, a diagnosis other than (classical) COPD should be considered. In addition, the presence of nasal polyps on examination or a history of recurrent surgery for nasal polyps may hint towards eosinophilic asthma [94]. Lastly, exacerbations that recur again and again after discontinuation of systemic corticosteroid courses are often a sign of corticosteroid dependency, which is a common feature of eosinophilic asthma $[14,15,61]$. Because the risk of misdiagnosis and inadequate treatment is highest amongst practitioners who are not familiar with the clinical presentation of a patient with eosinophilic asthma, like general practitioners or nurse practitioners, it is recommended that the type of airway inflammation should be assessed in all patients with COPD who have a limited smoking history, nasal polyps and/or recurrent exacerbations. More importantly, these patients should be referred to an asthma specialist for further assessment and targeted treatment [95].

Patients with eosinophilic asthma should ideally be diagnosed by analysing sputum samples [5]. However, sputum induction is not easy to perform in routine clinical practice and requires access to specific laboratories with trained personnel $[96,97]$. Therefore, the use of several alternatives to sputum cell counts, including peripheral blood eosinophils, exhaled nitric oxide fraction ( FeNO) and serum IgE have recently been evaluated in a systematic review [98]. The results show that overall, blood eosinophils, FeNO and IgE have only moderate accuracy to distinguish between patients with and without airway eosinophilia. Another recent study showed that in smoking and nonsmoking patients with adult-onset asthma, the diagnostic accuracies of FeNO and blood eosinophils were superior to that of total IgE, while combining FeNO and blood eosinophils into one model further improved the overall diagnostic accuracy [99]. A cut-off value of eosinophils of $<0.09 \times 10^{9} \mathrm{~L}^{-1}$ was associated with absence of airway eosinophilia in $92 \%$ of patients, whereas a value of $\geqslant 0.41 \times 10^{9} \mathrm{~L}^{-1}$ was associated with sputum eosinophils $\geqslant 3 \%$ in $95 \%$ of patients [99]. Blood eosinophilia, therefore, seems to be the most feasible surrogate marker to detect airway eosinophilia in patients with adult-onset airway disease in routine practice [14, 100, 101].

Patients with adult-onset, eosinophilic asthma should also be checked for chronic rhinosinusitis with nasal polyposis. Typically, patients with chronic rhinosinusitis and nasal polyps have an impaired sense of smell, which can be used as a tool to identify nasal polyposis in patients with eosinophilic asthma [102]. Diagnosis and management of chronic rhinosinusitis with nasal polyposis requires the expertise of a specialist [103]. Therefore, a patient with eosinophilic asthma should preferably be referred to an ear, nose and throat clinic soon after diagnosis.

Distal airway inflammation with air trapping and dynamic hyperinflation are also common in eosinophilic asthma, and should be addressed and treated if necessary. In a recent pilot study, fine-particle formulations were added to standard ICS treatment in patients with eosinophilic asthma to specifically target the distal airways [86]. The results showed that adding fine-formula ICS suppressed airway eosinophilia more than placebo, confirming earlier reports that eosinophilia in these patients is not entirely steroid resistant [87].

Finally, patients with eosinophilic asthma often depend on systemic corticosteroids for control of their disease [15]. It goes without saying that patients receiving this treatment chronically should receive preventive therapies for osteoporosis and peptic ulcers, and that they have to be checked regularly for weight gain, hypercholesterolaemia, hypertension and diabetes [104].

\section{New treatment options for the patient with eosinophilic asthma}

For patients with eosinophilic asthma, ICS, even at very high doses, are not sufficient to control the disease. It is for these often oral steroid-dependent patients that specific therapeutics targeting components of the inflammatory response have been developed or are currently under investigation. 


\section{Omalizumab}

Omalizumab is a monoclonal antibody that binds $\operatorname{IgE}$ and is, to date, the only biologic therapy approved for asthma. IgE has a central role in the pathophysiology of allergic responses, and omalizumab attenuates both the early- and late-phase responses to inhaled allergens in patients with asthma [105]. Although total serum IgE levels do not correlate with the degree of tissue eosinophilia, treatment with anti-IgE therapy has been shown to reduce airway and blood eosinophils and to be efficacious in reducing exacerbations in children, adolescents and adults with asthma [106-108]. However, there are patients with uncontrolled asthma that do not respond to anti-IgE therapy and show persistent eosinophilic inflammation. This is why therapeutics targeting Th2 cytokines, including IL-4, IL-5 and IL13, have been developed and tested in clinical trials in patients with eosinophilic asthma.

\section{Anti-IL-4 and anti-IL-13}

IL-4 and IL-13 play a key role in the pathogenesis of asthma, and several compounds aiming to target these cytokines are now being evaluated, of which the most promising will be discussed here [109].

Lebrikizumab and tralokinumab are both humanised monoclonal $\operatorname{IgG}_{4}$ antibodies to IL-13 and potent inhibitors of its function. CORREN et al. [110] evaluated the efficacy of lebrikizumab in a large trial in patients with moderate to severe asthma not controlled by ICS and showed a significant improvement in FEV1 in the subgroup with elevated periostin levels at baseline. Unfortunately, two more recent phase II trials in mild asthmatics were less promising and did not show any improvements in FEV1 or reduction in the late asthmatic response to allergen $[111,112]$. The failure of these last two trials suggests that patients with mild asthma whose asthma can be controlled by ICS are less likely to benefit from lebrikizumab.

Tralokinumab was evaluated in a large group of patients with moderate to severe asthma and, although there was no change in the primary end-point (asthma control), there was a statistically significant reduction in $\beta_{2}$-agonist use and increase in FEV1, in particular, in the subgroup of patients with elevated IL-13 levels in sputum [113].

These trials suggested that both tralokinumab and lebrikizumab may have beneficial effects on lung function in selected patients.

Therapies that inhibit both IL-4 and IL-13, including pitrakinra, a recombinant form of IL-4, and dupilumab, a monoclonal antibody to IL-4 receptor $\alpha$, have shown more promising results. A phase IIb study of pitrakinra in moderate to severe asthmatics demonstrated a reduction of exacerbation frequency among subgroups of patients with eosinophilic asthma, elevated exhaled nitric oxide levels and a specific IL-4 receptor polymorphism during withdrawal of ICS [114]. WenzeL et al. [59] evaluated the effect of dupilumab in patients with moderate to severe eosinophilic asthma during tapering of ICS and showed a significant reduction in asthma exacerbations, and improvements in lung function and asthma control. This latter proof-of-concept study suggests a potential role for dupilumab in a specific subset of patients with poorly controlled eosinophilic asthma.

\section{Anti-IL-5}

IL-5 plays a critical role in eosinophil differentiation, maturation, recruitment and activation in tissues [115]. This cytokine is extremely specific to eosinophils and has been an important therapeutic target in clinical asthma trials [116]. Several studies have investigated the effects of anti-IL-5 therapy in asthma. In 2000, LECKIE et al. [117] published a randomised, placebo-controlled, proof-of-principle study in 24 patients with mild allergic asthma, in which they showed that treatment with mepolizumab, a humanised monoclonal antibody to IL-5, resulted in a significant reduction in both circulating and sputum eosinophils. To the surprise of the investigators, IL-5 had no effect on the late asthmatic response to allergen challenge or on the associated increase in airway hyperresponsiveness. Two other studies, one relatively small dose-finding study and a large multicentre trial of 362 patients with mild allergic asthma [118], confirmed that mepolizumab was associated with a significant and sustained reduction in sputum and blood eosinophils, but without any effect on clinical asthma indices or measures of lung function. This lack of clinical effect of anti-IL-5 therapy was disappointing and questioned the role of eosinophils in asthma [117].

However, in 2009, by selecting patients with severe asthma and persistent blood and sputum eosinophilia, two independent studies were able to show a significant decrease in exacerbations and an improvement in asthma control with mepolizumab, in addition to a prednisone-sparing effect $[60,61]$. Both of these trials provided evidence that in a select group of asthma patients with severe "eosinophilic asthma", inhibition of IL-5 could result in clinically important benefits and set the stage for large, multicentre trials. A few years later, two large, multicentre trials evaluated the efficacy of mepolizumab in patients with evidence of eosinophilic airway inflammation and a history of recurrent, severe asthma exacerbations, and again showed around $50 \%$ reduction in exacerbation frequencies with corresponding decrease in peripheral blood 
eosinophils [13, 14]. In another large study among patients requiring oral glucocorticoids for asthma control, treatment with subcutaneous mepolizumab at 4 -week intervals over 20 weeks allowed for a significant reduction in steroid dose and a reduced exacerbation rate [15].

Besides mepolizumab, two other anti-IL-5 therapies have been developed and are also being studied in patients with poorly controlled eosinophilic asthma: reslizumab and benralizumab. Two large, phase III trials with reslizumab, a humanised $\mathrm{IgG}_{4}$ monoclonal antibody against IL-5, showed significant reductions in asthma exacerbations (50\% and 60\%, respectively), as well as improved lung function and asthma control symptoms $[119,120]$.

Benralizumab is a humanised monoclonal antibody against IL-5 receptor $\alpha$ on eosinophils and is currently in phase II trials. LAvioletTe et al. [121] examined the effect of a single $1-\mathrm{mg} \cdot \mathrm{kg}^{-1}$ dose of benralizumab given intravenously; they demonstrated that the drug was safe, and resulted in significant reductions in airway, bone marrow and peripheral blood eosinophilia for up to 28 days. Larger trials will determine if benralizumab has the same clinical benefits as mepolizumab and reslizumab.

\section{Conclusions}

Late-onset eosinophilic asthma is a relatively rare, but is one of the best-defined asthma phenotypes. Apart from elevated numbers of eosinophils in sputum and peripheral blood, adults with this phenotype can be clinically identified by typical symptoms (few allergies and dyspnoea on exertion), typical lung function abnormalities ("fixed" airflow obstruction, reduced FVC and increased residual volume), typical comorbidities (chronic rhinosinusitis with nasal polyposis) and a good response to systemic corticosteroids. Patients with eosinophilic asthma have a poor quality of life and many suffer from frequent severe exacerbations or are oral corticosteroid dependent. Fortunately, novel biologicals targeting the eosinophil have now become available and are, for the first time, able to control this type of refractory asthma, and to become a safe and efficacious substitute for oral corticosteroids. With these drugs, one of the greatest unmet needs in asthma will be eliminated and a new era of asthma treatment will begin.

\section{References}

Wenzel SE. Asthma: defining of the persistent adult phenotypes. Lancet 2006; 368: 804-813.

2 Hekking PP, Bel EH. Developing and emerging clinical asthma phenotypes. J Allergy Clin Immunol Pract 2014; 2: $671-680$.

3 Leynaert B, Sunyer J, Garcia-Esteban R, et al. Gender differences in prevalence, diagnosis and incidence of allergic and non-allergic asthma: a population-based cohort. Thorax 2012; 67: 625-631.

4 Moore WC, Bleecker ER, Curran-Everett D, et al. Characterization of the severe asthma phenotype by the National Heart, Lung, and Blood Institute's Severe Asthma Research Program. J Allergy Clin Immunol 2007; 119: 405-413.

5 Simpson JL, Scott R, Boyle MJ, et al. Inflammatory subtypes in asthma: assessment and identification using induced sputum. Respirology 2006; 11: 54-61.

6 Wenzel SE. Asthma phenotypes: the evolution from clinical to molecular approaches. Nat Med 2012; 18 : 716-725.

$7 \quad$ Pavord ID. Eosinophilic phenotypes of airway disease. Ann Am Thorac Soc 2013; 10: Suppl., S143-S149.

8 Amelink M, de Groot JC, de Nijs SB, et al. Severe adult-onset asthma: a distinct phenotype. J Allergy Clin Immunol 2013; 132: 336-341.

9 Lemiere C, Ernst P, Olivenstein R, et al. Airway inflammation assessed by invasive and noninvasive means in severe asthma: eosinophilic and noneosinophilic phenotypes. J Allergy Clin Immunol 2006; 118: 1033-1039.

10 Newby C, Agbetile J, Hargadon B, et al. Lung function decline and variable airway inflammatory pattern: longitudinal analysis of severe asthma. J Allergy Clin Immunol 2014; 134: 287-294.

11 Ten Brinke A, Zwinderman AH, Sterk PJ, et al. Factors associated with persistent airflow limitation in severe asthma. Am J Respir Crit Care Med 2001; 164: 744-748.

12 Tran TN, Khatry DB, Ke X, et al. High blood eosinophil count is associated with more frequent asthma attacks in asthma patients. Ann Allergy Asthma Immunol 2014; 113: 19-24.

13 Ortega HG, Liu MC, Pavord ID, et al. Mepolizumab treatment in patients with severe eosinophilic asthma. $N$ Engl J Med 2014; 371: 1198-1207.

14 Pavord ID, Korn S, Howarth P, et al. Mepolizumab for severe eosinophilic asthma (DREAM): a multicentre, double-blind, placebo-controlled trial. Lancet 2012; 380: 651-659.

15 Bel EH, Wenzel SE, Thompson PJ, et al. Oral glucocorticoid-sparing effect of mepolizumab in eosinophilic asthma. N Engl J Med 2014; 371: 1189-1197.

16 Rackemann FM. Intrinsic Asthma. Bull NY Acad Med 1947; 23: 302-306.

17 Lowell FC, Curry JJ, Schiller IW. A clinical and experimental study of isuprel in spontaneous and induced asthma. N Engl J Med 1948; 239: 45-51.

18 Rackemann FM, Mallory TB. Instrinsic asthma. Trans Am Clin Climatol Assoc 1941; 57: 60-73.

19 Burrows B, Martinez FD, Halonen M, et al. Association of asthma with serum IgE levels and skin-test reactivity to allergens. N Engl J Med 1989; 320: 271-277.

20 Anderson HR, Gupta R, Strachan DP, et al. 50 years of asthma: UK trends from 1955 to 2004. Thorax 2007; 62 $85-90$.

21 Grant EN, Wagner R, Weiss KB. Observations on emerging patterns of asthma in our society. J Allergy Clin Immunol 1999; 104: S1-S9.

22 Holgate ST. The epidemic of allergy and asthma. Nature 1999; 402: Suppl., B2-B4. 
Peat JK, Li J. Reversing the trend: reducing the prevalence of asthma. J Allergy Clin Immunol 1999; 103: 1-10. Harvey AM, Howard JE, Winkenwerder WL, et al. Observations on the effect of adrenocorticotrophic hormone (ACTH) on disseminated lupus erythematosus, drug hypersensitivity reactions, and chronic bronchial asthma. Trans Am Clin Climatol Assoc 1949; 61: 221-228.

Chu EK, Drazen JM. Asthma: one hundred years of treatment and onward. Am J Respir Crit Care Med 2005; 171: 1202-1208.

Godfrey S, Konig P. Beclomethasone aerosol in childhood asthma. Arch Dis Child 1973; 48: 665-670.

Barnes PJ, Woolcock AJ. Difficult asthma. Eur Respir J 1998; 12: 1209-1218.

Ten Brinke A, Sterk PJ, Masclee AA, et al. Risk factors of frequent exacerbations in difficult-to-treat asthma. Eur Respir J 2005; 26: 812-818

Miranda C, Busacker A, Balzar S, et al. Distinguishing severe asthma phenotypes: role of age at onset and eosinophilic inflammation. J Allergy Clin Immunol 2004; 113: 101-108.

Szczeklik A, Stevenson DD. Aspirin-induced asthma: advances in pathogenesis, diagnosis, and management. J Allergy Clin Immunol 2003; 111: 913-921.

Wenzel SE, Schwartz LB, Langmack EL, et al. Evidence that severe asthma can be divided pathologically into two inflammatory subtypes with distinct physiologic and clinical characteristics. Am J Respir Crit Care Med 1999; 160: 1001-1008.

Amelink M, de Nijs SB, de Groot JC, et al. Three phenotypes of adult-onset asthma. Allergy 2013; 68: 674-680.

Haldar P, Pavord ID, Shaw DE, et al. Cluster analysis and clinical asthma phenotypes. Am J Respir Crit Care Med 2008; 178: 218-224.

Moore WC, Meyers DA, Wenzel SE, et al. Identification of asthma phenotypes using cluster analysis in the Severe Asthma Research Program. Am J Respir Crit Care Med 2010; 181: 315-323.

Siroux V, Basagana X, Boudier A, et al. Identifying adult asthma phenotypes using a clustering approach. Eur Respir J 2011; 38: 310-317.

Carolan BJ, Sutherland ER. Clinical phenotypes of chronic obstructive pulmonary disease and asthma: recent advances. J Allergy Clin Immunol 2013; 131: 627-634.

Wenzel S. Severe asthma: from characteristics to phenotypes to endotypes. Clin Exp Allergy 2012; 42: 650-658 1033-1039.

Pin I, Freitag AP, O'Byrne PM, et al. Changes in the cellular profile of induced sputum after allergen-induced asthmatic responses. Am Rev Respir Dis 1992; 145: 1265-1269.

Durham SR, Craddock CF, Cookson WO, et al. Increases in airway responsiveness to histamine precede allergen-induced late asthmatic responses. J Allergy Clin Immunol 1988; 82: 764-770.

Aalbers R, Kauffman HF, Vrugt B, et al. Allergen-induced recruitment of inflammatory cells in lavage 3 and $24 \mathrm{~h}$ after challenge in allergic asthmatic lungs. Chest 1993; 103: 1178-1184.

Bacharier LB, Jabara H, Geha RS. Molecular mechanisms of immunoglobulin E regulation. Int Arch Allergy Immunol 1998; 115: 257-269.

Barrett NA, Austen KF. Innate cells and T helper 2 cell immunity in airway inflammation. Immunity 2009; 31: 425-437.

Li-Weber M, Krammer PH. Regulation of IL4 gene expression by T cells and therapeutic perspectives. Nat Rev Immunol 2003; 3: 534-543.

Zhu Z Homer RI, Wang Z, et al. Pulmonary expression of interleukin-13 causes inflammation, mucus hypersecretion, subepithelial fibrosis, physiologic abnormalities, and eotaxin production. J Clin Invest 1999; 103: 779-788.

Eum SY, Maghni K, Tolloczko B, et al. IL-13 may mediate allergen-induced hyperresponsiveness independently of IL-5 or eotaxin by effects on airway SM muscle. Am J Physiol Lung Cell Mol Physiol 2005; 288: L576-L584.

Barnes PJ. The cytokine network in asthma and chronic obstructive pulmonary disease. J Clin Invest 2008; 118: 3546-3556.

Sewell WA, Mu HH. Dissociation of production of interleukin-4 and interleukin-5. Immunol Cell Biol 1996; 74: 274-277.

Lambrecht BN, Hammad H. The immunology of asthma. Nat Immunol 2015; 16: 45-56.

Yu S, Kim HY, Chang YJ, et al. Innate lymphoid cells and asthma. J Allergy Clin Immunol 2014; 133: 943-950.

Brusselle GG, Maes T, Bracke KR. Eosinophils in the spotlight: eosinophilic airway inflammation in nonallergic asthma. Nat Med 2013; 19: 977-979.

Bartemes KR, Kephart GM, Fox SJ, et al. Enhanced innate type 2 immune response in peripheral blood from patients with asthma. J Allergy Clin Immunol 2014; 134: 671-678.

Mjosberg JM, Trifari S, Crellin NK, et al. Human IL-25- and IL-33-responsive type 2 innate lymphoid cells are defined by expression of CRTH2 and CD161. Nat Immunol 2011; 12: 1055-1062. eosinophilia. J Allergy Clin Immunol 2002; 109: 621-626. Walker JA, Barlow JL, McKenzie AN. Innate lymphoid cells - how did we miss them? Nat Rev Immunol 2013 13: 75-87.

Xue L, Salimi M, Panse I, et al. Prostaglandin $\mathrm{D}_{2}$ activates group 2 innate lymphoid cells through chemoattractant receptor-homologous molecule expressed on $\mathrm{T}_{\mathrm{H}} 2$ cells. J Allergy Clin Immunol 2014; 133: 1184-1194.

Christianson CA, Goplen NP, Zafar I, et al. Persistence of asthma requires multiple feedback circuits involving type 2 innate lymphoid cells and IL-33. J Allergy Clin Immunol 2015 [In press DOI: 10.1016/j.jaci.2014.11.037].

Schleich F, Brusselle G, Louis R, et al. Heterogeneity of phenotypes in severe asthmatics. The Belgian Severe Asthma Registry (BSAR). Respir Med 2014; 108: 1723-1732.

Wenzel S, Ford L, Pearlman D, et al. Dupilumab in persistent asthma with elevated eosinophil levels. $N$ Engl J Med 2013; 368: 2455-2466.

Haldar P, Brightling CE, Hargadon B, et al. Mepolizumab and exacerbations of refractory eosinophilic asthma. N Engl J Med 2009; 360: 973-984.

ir P, Pizzichini MM, Kjarsgaard M, et al. Mepolizumab for prednisone-dependent asthma with sputum eosinophilia. N Engl J Med 2009; 360: 985-993 
van Veen IH, Ten Brinke A, Gauw SA, et al. Consistency of sputum eosinophilia in difficult-to-treat asthma: a 5-year follow-up study. J Allergy Clin Immunol 2009; 124: 615-617.

63 Hekking PP, Wener RR, Amelink M, et al. The prevalence of severe refractory asthma. J Allergy Clin Immunol 2015; 135: 896-902.

64 Dodge RR, Burrows B. The prevalence and incidence of asthma and asthma-like symptoms in a general population sample. Am Rev Respir Dis 1980; 122: 567-575.

65 De Carvalho-Pinto RM, Cukier A, Angelini L, et al. Clinical characteristics and possible phenotypes of an adult severe asthma population. Respir Med 2012; 106: 47-56.

66 Barnes PJ. Intrinsic asthma: not so different from allergic asthma but driven by superantigens? Clin Exp Allergy 2009; 39: 1145-1151.

67 Yoo HS, Shin YS, Liu JN, et al. Clinical significance of immunoglobulin E responses to staphylococcal superantigens in patients with aspirin-exacerbated respiratory disease. Int Arch Allergy Immunol 2013; 162: 340-345.

68 Romagnoli M, Vachier I, Tarodo de la Fuente P, et al. Eosinophilic inflammation in sputum of poorly controlled asthmatics. Eur Respir J 2002; 20: 1370-1377.

69 Volbeda F, Broekema M, Lodewijk ME, et al. Clinical control of asthma associates with measures of airway inflammation. Thorax 2013; 68: 19-24

70 Meijer RJ, Postma DS, Kauffman HF, et al. Accuracy of eosinophils and eosinophil cationic protein to predict steroid improvement in asthma. Clin Exp Allergy 2002; 32: 1096-1103.

71 Wenzel S. Severe/fatal asthma. Chest 2003; 123: Suppl., 405S-410S.

72 Carroll N, Cooke C, James A. The distribution of eosinophils and lymphocytes in the large and small airways of asthmatics. Eur Respir J 1997; 10: 292-300.

73 Bumbacea D, Campbell D, Nguyen L, et al. Parameters associated with persistent airflow obstruction in chronic severe asthma. Eur Respir J 2004; 24: 122-128.

74 van Veen IH, Ten Brinke A, Sterk PJ, et al. Exhaled nitric oxide predicts lung function decline in difficult-to-treat asthma. Eur Respir J 2008; 32: 344-349.

75 Berry MA, Shaw DE, Green RH, et al. The use of exhaled nitric oxide concentration to identify eosinophilic airway inflammation: an observational study in adults with asthma. Clin Exp Allergy 2005; 35: 1175-1179.

76 Jarvis D, Newson R, Lotvall J, et al. Asthma in adults and its association with chronic rhinosinusitis: the GA²LEN survey in Europe. Allergy 2012; 67: 91-98.

77 Samter M, Beers RF, Jr. Concerning the nature of intolerance to aspirin. J Allergy 1967; 40: 281-293.

78 Demoly P, Crampette L, Mondain M, et al. Assessment of inflammation in noninfectious chronic maxillary sinusitis. J Allergy Clin Immunol 1994; 94: 95-108.

79 Hamilos DL, Leung DY, Wood R, et al. Evidence for distinct cytokine expression in allergic versus nonallergic chronic sinusitis. J Allergy Clin Immunol 1995; 96: 537-544.

80 Harlin SL, Ansel DG, Lane SR, et al. A clinical and pathologic study of chronic sinusitis: the role of the eosinophil. J Allergy Clin Immunol 1988; 81: 867-875.

81 Moneret-Vautrin DA, Jankowski R, Bene MC, et al. NARES: a model of inflammation caused by activated eosinophils? Rhinology 1992; 30: 161-168.

82 Iino Y. Eosinophilic otitis media: a new middle ear disease entity. Curr Allergy Asthma Rep 2008; 8: 525-530.

83 Iino Y, Nagamine H, Yabe T, et al. Eosinophils are activated in middle ear mucosa and middle ear effusion of patients with intractable otitis media associated with bronchial asthma. Clin Exp Allergy 2001; 31: 1135-1143.

84 Leach CL, Davidson PJ, Boudreau RJ. Improved airway targeting with the CFC-free HFA-beclomethasone metered-dose inhaler compared with CFC-beclomethasone. Eur Respir J 1998; 12: 1346-1353.

85 Richards J, Hirst P, Pitcairn G, et al. Deposition and pharmacokinetics of flunisolide delivered from pressurized inhalers containing non-CFC and CFC propellants. J Aerosol Med 2001; 14: 197-208.

86 Hodgson D, Anderson J, Reynolds C, et al. A randomised controlled trial of small particle inhaled steroids in refractory eosinophilic asthma (SPIRA). Thorax 2015; 70: 559-565.

87 Ten Brinke A, Zwinderman AH, Sterk PJ, et al. "Refractory" eosinophilic airway inflammation in severe asthma: effect of parenteral corticosteroids. Am J Respir Crit Care Med 2004; 170: 601-605.

88 Green RH, Brightling CE, McKenna S, et al. Asthma exacerbations and sputum eosinophil counts: a randomised controlled trial. Lancet 2002; 360: 1715-1721.

89 Jayaram L, Pizzichini MM, Cook RJ, et al. Determining asthma treatment by monitoring sputum cell counts: effect on exacerbations. Eur Respir J 2006; 27: 483-494.

90 Wenzel SE. Eosinophils in asthma - closing the loop or opening the door? N Engl J Med 2009; 360: 1026-1028.

91 Veen JC, Smits HH, Ravensberg AJ, et al. Impaired perception of dyspnea in patients with severe asthma. Relation to sputum eosinophils. Am J Respir Crit Care Med 1998; 158: 1134-1141.

92 Abramson MJ, Perret JL, Dharmage SC, et al. Distinguishing adult-onset asthma from COPD: a review and a new approach. Int J Chron Obstruct Pulmon Dis 2014; 9: 945-962.

93 Suissa S, Ernst P, Benayoun S, et al. Low-dose inhaled corticosteroids and the prevention of death from asthma. N Engl J Med 2000; 343: 332-336.

94 Wu W, Bleecker E, Moore W, et al. Unsupervised phenotyping of Severe Asthma Research Program participants using expanded lung data. J Allergy Clin Immunol 2014; 133: 1280-1288.

95 Sweeney J, Brightling CE, Menzies-Gow A, et al. Clinical management and outcome of refractory asthma in the UK from the British Thoracic Society Difficult Asthma Registry. Thorax 2012; 67: 754-756.

96 Ten Brinke A, de Lange C, Zwinderman AH, et al. Sputum induction in severe asthma by a standardized protocol: predictors of excessive bronchoconstriction. Am J Respir Crit Care Med 2001; 164: 749-753.

97 Pin I, Gibson PG, Kolendowicz R, et al. Use of induced sputum cell counts to investigate airway inflammation in asthma. Thorax 1992; 47: 25-29.

98 Korevaar DA, Westerhof GA, Wang J, et al. Diagnostic accuracy of minimally invasive markers for detection of airway eosinophilia in asthma: a systematic review and meta-analysis. Lancet Respir Med 2015; 3: 290-300.

99 Westerhof GA, Korevaar DA, Amelink M, et al. Biomarkers to identify sputum eosinophilia in different adult asthma phenotypes. Eur Respir J 2015; [In press DOI: 10.1183/09031936.00012415].

100 Katz LE, Gleich GJ, Hartley BF, et al. Blood eosinophil count is a useful biomarker to identify patients with severe eosinophilic asthma. Ann Am Thorac Soc 2014; 11: 531-536. 
Zhang XY, Simpson JL, Powell H, et al. Full blood count parameters for the detection of asthma inflammatory phenotypes. Clin Exp Allergy 2014; 44: 1137-1145.

102 Alobid I, Cardelus S, Benitez P, et al. Persistent asthma has an accumulative impact on the loss of smell in patients with nasal polyposis. Rhinology 2011; 49: 519-524.

103 Fokkens WJ, Lund VJ, Mullol J, et al. European position paper on rhinosinusitis and nasal polyps 2012. Rhinol Suppl 2012; 23: 1-298.

104 Manson SC, Brown RE, Cerulli A, et al. The cumulative burden of oral corticosteroid side effects and the economic implications of steroid use. Respir Med 2009; 103: 975-994.

105 Noga O, Hanf G, Brachmann I, et al. Effect of omalizumab treatment on peripheral eosinophil and T-lymphocyte function in patients with allergic asthma. J Allergy Clin Immunol 2006; 117: 1493-1499.

106 Djukanovic R, Wilson SJ, Kraft M, et al. Effects of treatment with anti-immunoglobulin E antibody omalizumab on airway inflammation in allergic asthma. Am J Respir Crit Care Med 2004; 170: 583-593.

107 Massanari M, Milgrom H, Pollard S, et al. Adding omalizumab to the therapy of adolescents with persistent uncontrolled moderate--severe allergic asthma. Clin Pediatr (Phila) 2009; 48: 859-865.

108 Noga O, Hanf G, Kunkel G. Immunological and clinical changes in allergic asthmatics following treatment with omalizumab. Int Arch Allergy Immunol 2003; 131: 46-52.

109 Oh CK, Geba GP, Molfino N. Investigational therapeutics targeting the IL-4/IL-13/STAT-6 pathway for the treatment of asthma. Eur Respir Rev 2010; 19: 46-54.

110 Corren J, Lemanske RF, Hanania NA, et al. Lebrikizumab treatment in adults with asthma. N Engl J Med 2011; 365: 1088-1098.

111 Noonan M, Korenblat P, Mosesova S, et al. Dose-ranging study of lebrikizumab in asthmatic patients not receiving inhaled steroids. J Allergy Clin Immunol 2013; 132: 567-574.

112 Scheerens H, Arron JR, Zheng Y, et al. The effects of lebrikizumab in patients with mild asthma following whole lung allergen challenge. Clin Exp Allergy 2014; 44: 38-46.

113 Piper E, Brightling C, Niven R, et al. A phase II placebo-controlled study of tralokinumab in moderate-to-severe asthma. Eur Respir J 2013; 41: 330-338.

114 Slager RE, Otulana BA, Hawkins GA, et al. IL-4 receptor polymorphisms predict reduction in asthma exacerbations during response to an anti-IL-4 receptor $\alpha$ antagonist. J Allergy Clin Immunol 2012; 130: 516-522.

115 Menzies-Gow A, Flood-Page P, Sehmi R, et al. Anti-IL-5 (mepolizumab) therapy induces bone marrow eosinophil maturational arrest and decreases eosinophil progenitors in the bronchial mucosa of atopic asthmatics. J Allergy Clin Immunol 2003; 111: 714-719.

116 Rosenberg HF, Phipps S, Foster PS. Eosinophil trafficking in allergy and asthma. J Allergy Clin Immunol 2007; 119: $1303-1310$.

117 Leckie MJ, ten Brinke A, Khan J, et al. Effects of an interleukin-5 blocking monoclonal antibody on eosinophils, airway hyper-responsiveness, and the late asthmatic response. Lancet 2000; 356: 2144-2148.

118 Flood-Page P, Swenson C, Faiferman I, et al. A study to evaluate safety and efficacy of mepolizumab in patients with moderate persistent asthma. Am J Respir Crit Care Med 2007; 176: 1062-1071.

119 Castro M, Zangrilli J, Wechsler ME, et al. Reslizumab for inadequately controlled asthma with elevated blood eosinophil counts: results from two multicentre, parallel, double-blind, randomised, placebo-controlled, phase 3 trials. Lancet Respir Med 2015; 3: 355-366.

120 Castro M, Mathur S, Hargreave F, et al. Reslizumab for poorly controlled, eosinophilic asthma: a randomized, placebo-controlled study. Am J Respir Crit Care Med 2011; 184: 1125-1132.

121 Laviolette M, Gossage DL, Gauvreau G, et al. Effects of benralizumab on airway eosinophils in asthmatic patients with sputum eosinophilia. J Allergy Clin Immunol 2013; 132: 1086-1096. 